\title{
Coronary artery thrombosis in patients with unstable angina
}

\author{
DAVID R HOLMES JR, GEOFFREY O HARTZLER, HUGH C SMITH, \\ VALENTIN FUSTER
}

From the Mayo Clinic and Mayo Foundation, Rochester, Minnesota, USA

SUMMARY This report describes the clinical course, coronary artery anatomy, and ventricular function of 16 patients in whom coronary artery thrombosis was detected at the time of cardiac catheterisation. All patients had an unstable clinical course in which accelerated angina occurred a mean of four weeks (range four days to 12 weeks) before catheterisation, and four patients had recent subendocardial myocardial infarction. In all patients severe coronary artery disease was documented at catheterisation. Fifteen patients had segmental wall motion abnormalities involving the left ventricular wall that was supplied by the coronary artery in which there was thrombus. Three patterns of coronary artery thrombus were noted: (1) thrombus proximal to high-grade coronary artery stenosis; (2) thrombus distal to highgrade coronary artery stenosis; and (3) thrombus in segments of the arterial tree in which there was no high-grade coronary artery stenosis. Though the precise cause of the coronary artery thrombosis in our patients is unknown, it may have been a result of stasis, a ruptured atherosclerotic plaque, or coronary spasm. The common clinical course with unstable angina of acute onset suggests the possibility that the thrombus may have been responsible for the abrupt change in clinical condition or may have been a contributing factor in the patients' course.

The significance of coronary artery thrombosis in the pathophysiology of ischaemic heart disease remains controversial. Various authors have reported on the incidence of intracoronary thrombus in patients with transmural myocardial infarction, ${ }^{1-11}$ subendocardial myocardial infarction, ${ }^{510}$ and sudden coronary death, ${ }^{5912-14}$ but the cause or effect relation remains uncertain. In the past, detection of coronary thrombus has been difficult and patients have been identified mainly at the time of necropsy. There is little information available concerning the clinical setting and significance of coronary thrombus detected during life. This report describes the clinical course of 16 patients who were deemed to have coronary thrombus which was detected at the time of cardiac catheterisation.

\section{Subjects and methods}

During a three year period 1976 to 1979,16 of a total of 3553 patients undergoing cardiac catheterisation for suspected coronary artery disease were found to have a radiolucent central filling defect that was consistent with coronary artery thrombus. The angiographic recognition of intra-

Received for publication 17 September 1980 coronary thrombus is subjective. Certain features however, exist which allow differentiation from atheromatous disease and strongly suggest the presence of intraluminal thrombus. These features include: (1) the presence of a smooth central filling defect surrounded by contrast material (Renografin) seen in multiple projections; and (2) the absence of calcification within the defect. Limited pathological confirmation (see Results) in these patients supports these criteria. The clinical course, location of thrombus, coronary anatomy, and left ventricular function in these 16 patients were analysed.

Catheterisation was performed with the use of the Sones or the Judkins technique. No patient had coronary thromboembolism related to the catheterisation as judged by (1) lack of other emboli; (2) absence of prolonged angina during the study; and (3) lack of electrocardiographic evidence of myocardial infarction occurring during the catheterisation.

\section{Results}

As can be seen from Table 1, there were 13 men and three women with a mean age of 61.3 years. The indication for cardiac catheterisation in all patients 
Table 1 Clinical characteristics

\begin{tabular}{|c|c|c|c|c|c|}
\hline $\begin{array}{l}\text { Case } \\
\text { no. }\end{array}$ & Sex & $\begin{array}{l}\text { Age } \\
(y)\end{array}$ & $\begin{array}{l}\text { Associated } \\
\text { cardiovascular } \\
\text { disease }\end{array}$ & $\begin{array}{l}\text { Previous angina } \\
\text { or infarction }\end{array}$ & $\begin{array}{l}\text { Onset of } \\
\text { symptoms before } \\
\text { catheterisation }\end{array}$ \\
\hline $\begin{array}{l}1 \\
2\end{array}$ & $\begin{array}{l}\mathbf{F} \\
\mathbf{F}\end{array}$ & $\begin{array}{l}61 \\
67\end{array}$ & $\begin{array}{l}\text { None } \\
\text { History of } \\
\text { constrictive } \\
\text { pericarditis }\end{array}$ & $\begin{array}{l}\text { None } \\
\text { None }\end{array}$ & $\begin{array}{l}3 \mathrm{wk} \\
6 \mathrm{wk}\end{array}$ \\
\hline 3 & $\mathbf{M}$ & 59 & None & $\begin{array}{l}\text { Interior infarct } \\
11 \mathrm{y} \text { before } \\
\text { cath }\end{array}$ & $4 d$ \\
\hline 4 & $\mathbf{M}$ & 63 & None & None & $6 \mathrm{wk}$ \\
\hline 5 & $\mathbf{M}$ & 61 & None & None & 8 wk \\
\hline 6 & $\mathbf{M}$ & 63 & Aortic stenosis & None & 8 wk \\
\hline 7 & $\mathbf{M}$ & 65 & None & & 2 wk \\
\hline 8 & $\mathbf{F}$ & 73 & ASO & $\begin{array}{l}\text { Interior infarct } \\
4 \mathrm{y} \text { before } \\
\text { cath }\end{array}$ & 4 wk \\
\hline 9 & $\mathbf{M}$ & 56 & None & $\begin{array}{l}\text { Inferior infarct } \\
10 \mathrm{y} \text { before } \\
\text { cath }\end{array}$ & $12 \mathrm{wk}$ \\
\hline 10 & $\mathbf{M}$ & 50 & None & None & $2 \frac{1}{2} \mathrm{wk}$ \\
\hline 11 & $\mathbf{M}$ & 65 & None & None & 2 wk \\
\hline 12 & $\mathbf{M}$ & 61 & None & $\begin{array}{l}\text { Stable angina } \\
\text { for } 5 \mathrm{mth}\end{array}$ & 2 wk \\
\hline 13 & $\mathbf{M}$ & 58 & None & $\begin{array}{l}\text { Anteroseptal } \\
\text { infarction } 4 \mathrm{y} \\
\text { before cath }\end{array}$ & 1 wk \\
\hline 14 & $\mathbf{M}$ & 58 & None & None & $2 \frac{1}{2} \mathrm{wk}$ \\
\hline $\begin{array}{l}15 \\
16\end{array}$ & $\begin{array}{l}M \\
M\end{array}$ & $\begin{array}{l}65 \\
57\end{array}$ & $\begin{array}{l}\text { None } \\
\text { None }\end{array}$ & $\begin{array}{l}\text { None } \\
\text { ASHD S/P }\end{array}$ & $\begin{array}{l}3 \mathrm{wk} \\
3 \mathrm{wk}\end{array}$ \\
\hline & & & & $\begin{array}{l}\text { SVBPG to LAD } \\
4 \text { y before cath }\end{array}$ & \\
\hline
\end{tabular}

ASO, arteriosclerosis obliterans; ASHD, arteriosclerotic heart disease; SVBPG, saphenous vein bypass graft; LAD, left anterior descending coronary artery; $S / P$, status post.

was the onset of increasingly frequent and severe angina despite conventional medical treatment. Fifteen of the 16 patients had the onset of acute symptoms within two months of catheterisation and fulfilled the Coronary Artery Surgery Study definition of unstable angina.* The remaining patient had the onset of increasingly frequent and severe angina beginning three months before the catheterisation. Five patients had known ischaemic heart disease before the onset of acute symptoms, while in the remaining patients the angina was of new onset. Thirteen patients had angina at rest; none of these, however, had the clinical features of Prinzmetal's angina. Despite conventional medical treatment in hospital, 12 patients continued to have angina before catheterisation. Four patients had sustained recent subendocardial myocardial infarction, but no patient had uncontrolled congestive heart failure or rhythm disturbance.

Severe coronary artery disease, with more than 50 per cent reduction in lumen diameter of at least

*The definition of unstable angina is found in the Manual of Operations of Coronary Artery Surgery Study. "Unstable angina or a substantially new pattern of chest pain which began in the past two months. The last episode of chest pain should have occurred within the week prior to the initial study hospitalization and without the patient having had electrocardiographic changes or elevated cardiac enzymes reflecting a recent myocardial infarction." one coronary artery, was present at the time of cardiac catheterisation in all 16 patients (Table 2). Six had triple-vessel disease, eight had involvement of two vessels, and two had single-vessel disease. Normal left ventricular wall motion was seen in one patient. The remaining 15 patients had segmental wall motion abnormalities involving the left ventricular wall that was supplied by the coronary artery in which there was thrombus. Fourteen of these 15 patients had additional segmental wall motion abnormalities in areas not supplied by the coronary artery involved with thrombus.

Thrombi (Table 2) were found in the right coronary artery in six patients (Fig. 1), in the left anterior descending coronary artery in five patients (Fig. 2), and in the circumflex system in five patients (Fig. 3 and 4). There was no evidence of distal embolisation in the distribution of the coronary artery involved. No thrombus resulted in complete occlusion of the coronary artery, but all resulted in 50 per cent or greater obstruction at the site. Three patterns of thrombus were noted: (1) thrombus proximal to high-grade coronary artery stenosis, four patients; (2) thrombus distal to highgrade stenosis, seven patients, and (3) thrombus occurring in a coronary artery segment in which there was no associated coronary artery stenosis of 50 per cent or more, five patients.

Pathological confirmation of the coronary artery thrombus was obtained in three patients. Of these, angiographically documented right coronary artery thrombi were removed at the time of operation in two patients (Fig. 5). Histological examination was

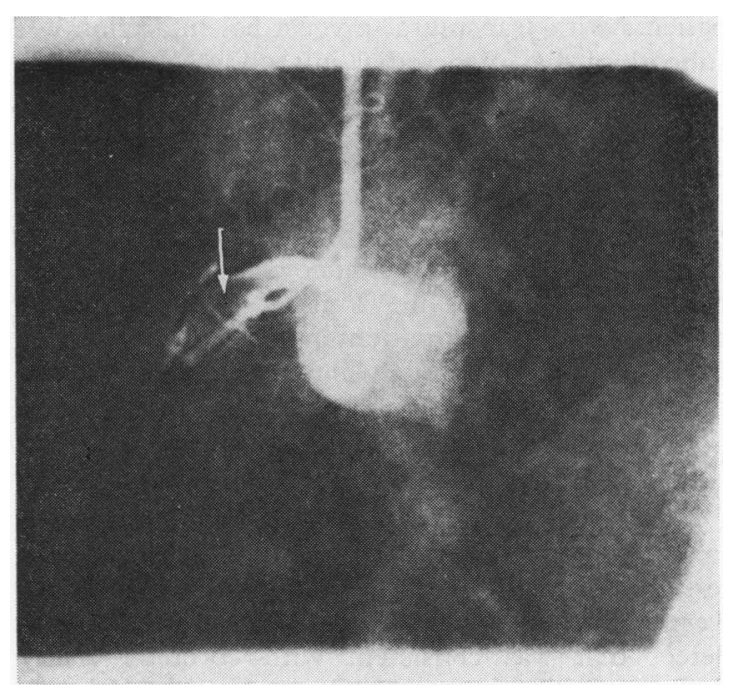

Fig. 1 Left anterior oblique view showing thrombus in right coronary artery proximal to occlusion. 


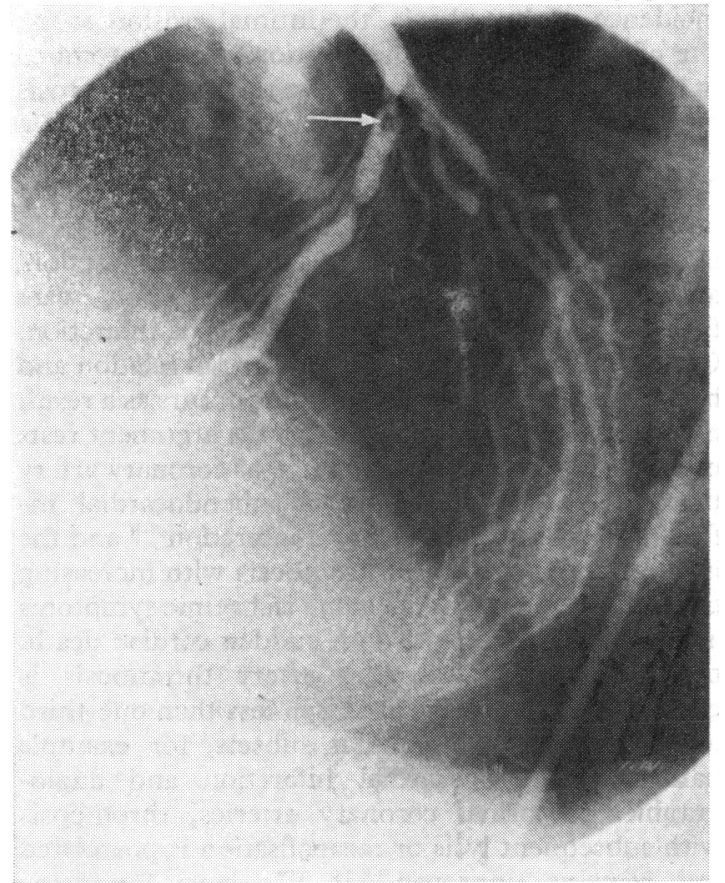

Fig. 2 Left anterior oblique view showing thrombus in left anterior descending coronary artery distal to high-grade stenosis. There is also high-grade stenosis distal to thrombus. consistent with a recent thrombus in both. The third patient died suddenly, presumably from an arrhythmic event, 24 hours after catheterisation. Angiography had documented a proximal right

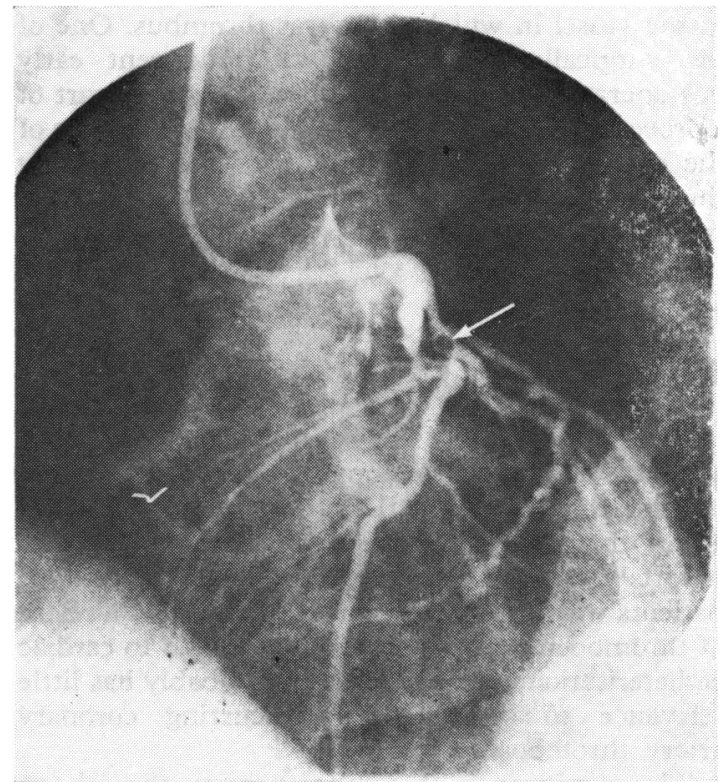

Fig. 3 Left anterior oblique view showing thrombus in proximal circumflex system.

\section{Table 2 Coronary artery anatomy}

\begin{tabular}{|c|c|c|c|c|}
\hline $\begin{array}{l}\text { Case } \\
\text { no. }\end{array}$ & $\begin{array}{l}\text { Vessels involved with } \\
\text { significant }{ }^{\star} \text { coronary } \\
\text { artery disease }\end{array}$ & Location of thrombus & $\begin{array}{l}\text { Luminal } \\
\text { narrowing by } \\
\text { thrombus }(\%)\end{array}$ & Relation of thrombus to coronary artery disease \\
\hline 1 & RCA & Proximal LAD & 90 & $\begin{array}{l}\text { No significant atherosclerotic narrowing near area of } \\
\text { thrombus }\end{array}$ \\
\hline 2 & RCA, circ & Proximal circ & 90 & Proximal to $60 \%$ stenosis \\
\hline 3 & RCA, circ, LAD & Proximal circ & $\geqslant 95$ & Distal to $\geqslant 95 \%$ stenosis \\
\hline 4 & LAD, circ & Proximal LAD & 80 & Distal to $\geqslant 95 \%$ stenosis \\
\hline 6 & LAD, circ & Proximal RCA & $\geqslant 95$ & $\begin{array}{l}\text { No significant atherosclerotic narrowing near area of } \\
\text { thrombus }\end{array}$ \\
\hline 7 & RCA, LAD, circ & Proximal RCA & 90 & Proximal to occlusion of RCA \\
\hline 8 & LAD, circ & Proximal and mid-RCA & $\geqslant 95$ & $\begin{array}{l}\text { No significant atherosclerotic narrowing near area of } \\
\text { thrombus }\end{array}$ \\
\hline 9 & LAD, circ, RCA & Proximal RCA & 95 & Distal to $\geqslant 95 \%$ stenosis \\
\hline 10 & LAD, diag & Proximal RCA & $\geqslant 95$ & $\begin{array}{l}\text { No significant atherosclerotic narrowing near area of } \\
\text { thrombus }\end{array}$ \\
\hline 12 & LAD, RCA, circ & Proximal obtuse marginal & 80 & Distal to $\geqslant 95 \%$ stenosis \\
\hline 13 & RCA & Proximal LAD & $\geqslant 95$ & $\begin{array}{l}\text { No significant atherosclerotic narrowing near area of the } \\
\text { thrombus }\end{array}$ \\
\hline 14 & Circ, LAD & Middle LAD & 70 & Distal to $\geqslant 95 \%$ stenosis \\
\hline 15 & LAD, RCA & Distal RCA & 70 & Distal to $\geqslant 95 \%$ stenosis \\
\hline 16 & LAD, circ & Distal circ & $\geqslant 95$ & Proximal to $\geqslant 95 \%$ stenosis \\
\hline
\end{tabular}

$\star \geqslant 50 \%$ stenosis.

LAD, left anterior descending coronary artery; RCA, right coronary artery; circ, circumflex coronary artery. 
coronary artery thrombus, which was confirmed at the time of necropsy.

Twelve patients underwent saphenous vein bypass graft surgery with a mean of 2.4 grafts per patient. In all patients a graft was placed distally in the vessel in which there was thrombus. One of the surgically treated patients underwent early postoperative (two weeks) catheterisation as part of a procedure to evaluate graft patency. At the time of the early postoperative study, the coronary artery thrombus was still present. Three patients were treated medically.

\section{Discussion}

Although evidence for the role of coronary artery thrombosis in the pathophysiology of arteriosclerotic heart disease has been gained from several sources including necropsy series and animal models, there is very little information on coronary artery thrombosis shown by angiography. Several reports ${ }^{15} 16$ have documented the clinical course of patients with coronary artery thrombosis as a result of thromboembolic complications related to cardiac catheterisation, but this situation probably has little relevance to spontaneously occurring coronary artery thrombosis.

The significance of coronary artery thrombosis appears to depend on the clinical setting. In fatal infarction, the incidence of coronary artery thrombosis varies. Some authors have found that the majority of patients dying with myocardial infarction have coronary artery thrombosis. The high

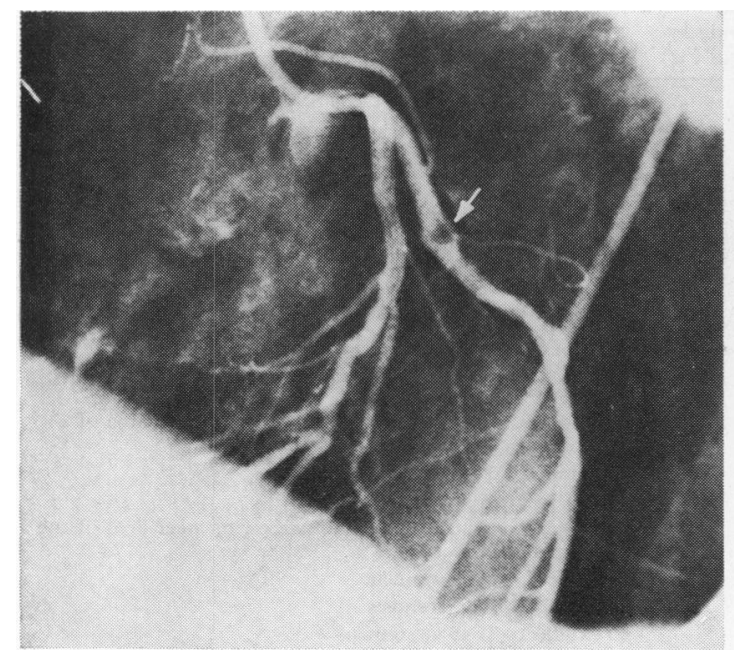

Fig. 4 Left anterior oblique view showing thrombus in the proximal circumflex. incidence of thrombosis, the intimal erosion at the site of thrombus, and the location of the thrombus in the coronary artery supplying the area of necrosis have been the basis for the argument that there is a cause-and-effect relation. ${ }^{1-4}$ In addition, Fulton and Sumner, ${ }^{17}$ using radiofibrinogen, have shown central radionegative cores in occlusive thrombi in coronary arteries supplying areas of acute infarction, and this finding suggests that the thrombi were formed early and may have preceded the infarction. Other authors have disputed this causal relation and have maintained that the thrombus occurs as a result of the infarction..$^{5-9}$ Support for this argument rests on the finding of a low incidence of coronary artery thrombosis not only in fatal subendocardial infarction but also in transmural infarction ${ }^{5-8}$ and the increase in frequency of thrombosis with increasing time between the onset of acute ischaemic symptoms and death. ${ }^{9}$ In patients with sudden cardiac death, the incidence of coronary artery thrombosis is considerably lower, occurring in less than one-third of the cases..$^{1214}$ In other subsets, for example patients with myocardial infarction and angiographically normal coronary arteries, thrombosis with subsequent lysis or recanalisation is postulated but remains unproven. ${ }^{1819}$ We have found no published observations on the possible role of coronary artery thrombosis in unstable angina.

The cause of coronary artery thrombosis is con-

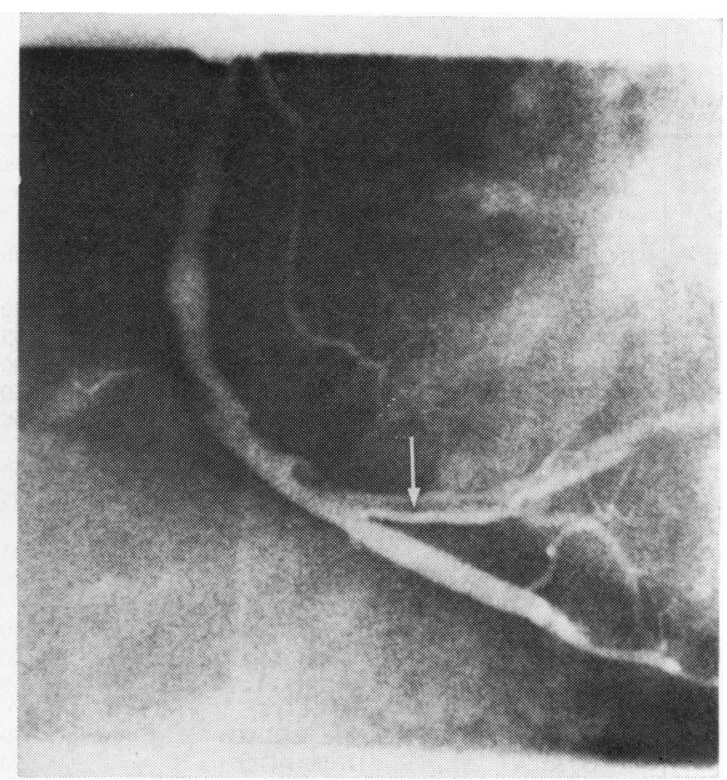

Fig. 5 Left anterior oblique view showing thrombus in right coronary artery. Thrombus was removed at time of operation. 
troversial. The pathological association between thrombus and a ruptured atheromatous plaque has led to the postulate that rupture of the plaque may cause platelet adhesion, platelet aggregation, release of tissue thromboplastin, and subsequent thrombosis. ${ }^{21}{ }^{21}$ It has been suggested that coronary artery spasm may either cause the rupture of the plaque ${ }^{20} 22$ or result in stasis that eventually leads to thrombus formation. ${ }^{23}$ In our patients there are several possibilities. The location of thrombus distal to a high-grade stenosis may imply stasis as a cause. It is possible that in these patients the stenosis itself was part of a thrombotic process that had occurred at an earlier time, producing the change in symptoms, but that had become adherent, organised, and indistinguishable angiographically from atherosclerotic narrowing. In those patients in whom thrombus was seen in a segment of the arterial tree without severe coronary artery disease, a ruptured plaque or coronary spasm with subsequent stasis may have been the cause of the thrombus.

The frequency with which coronary artery thrombus occurs is unknown. During the period in which these patients were identified, 1202 patients underwent angiography for evaluation of an unstable clinical course defined as progressive escalation in the frequency and severity of angina pectoris in a three-month period before catheterisation despite conventional medical treatment. The 16 patients identified here represent 1.3 per cent of these 1202 patients. This incidence of 1.3 per cent may be artificially low because of the inherent insensitivity of angiography in detecting thrombus. Our criteria for the diagnosis of coronary thrombus include an intraluminal filling defect that is separate from the arterial wall. Thrombi that are adherent or moulded to the wall may not be distinguishable from an atherosclerotic plaque. Moreover, the incidence of coronary artery thrombosis in all patients with an unstable clinical course is uncertain because not all patients with this problem undergo angiography.

In the patients presented here, the treatment regimen was based on the clinical course, coronary artery anatomy, and ventricular function rather than on the basis of thrombus. All 13 patients who underwent surgery had grafts placed in the vessel involved with thrombus. The importance of anticoagulant or thrombolytic treatment in either the medically or the surgically treated groups remains to be determined.

The precise significance of coronary artery thrombosis in the cases described here is unknown. In four patients the thrombus was visualised between six and 12 weeks after the onset of the clinical syndrome. It could be argued that if the thrombus was responsible for the clinical syndrome it might have undergone resolution or organisation and have become difficult to distinguish angiographically from an atherosclerotic plaque. The time required for this, however, is unknown. The common course with the abrupt and recent onset of increasingly frequent and severe angina leads us to believe that the thrombus may have been responsible for the abrupt change in clinical condition or may have been a contributing factor in the patients' course.

\section{References}

1 Horie $T$, Sekiguchi $M$, Hirosawa $K$. Coronary thrombosis in pathogenesis of acute myocardial infarction: histopathological study of coronary arteries in 108 necropsied cases using serial section. Br Heart f 1978; 40: 153-61.

2 Chandler AB, Chapman I, Erhardt LR, et al. Coronary thrombosis in myocardial infarction: report of a workshop on the role of coronary thrombosis in the pathogenesis of acute myocardial infarction. Am $\mathcal{F}$ Cardiol 1974; 34: 823-32.

3 Chapman I. The cause-effect relationship between recent coronary artery occlusion and acute myocardial infarction. Am Heart f 1974; 87: 267-71.

4 Horie T, Sekiguchi M, Hirosawa K. Relationship between myocardial infarction and preinfarction angina: a histopathological study of coronary arteries in two sudden death cases employing serial section. Am Heart f 1978; 95: 81-8.

5 Roberts WC, Buja LM. The frequency and significance of coronary arterial thrombi and other observations in fatal acute myocardial infarction: a study of 107 necropsy patients. Am f Med 1972; 52: 425-43.

6 Roberts WC. Coronary thrombosis and fatal myocardial ischemia (editorial). Circulation 1974; 49: $1-3$.

7 Branwood AW. The development of coronary thrombosis following myocardial infarction. Lipids 1978; 13: 378-9.

8 Baroldi G. Coronary thrombosis: facts and beliefs (editorial). Am Heart $\mathcal{7}$ 1976; 91: 683-8.

9 Spain DM, Bradess VA. The relationship of coronary thrombosis to coronary atherosclerosis and ischemic heart disease (a necropsy study covering a period of 25 years). Am f Med Sci 1960; 240: 701-10.

10 Davies MJ, Woolf N, Robertson WB. Pathology of acute myocardial infarction with particular reference to occlusive coronary thrombi. $\mathrm{Br}$ Heart $\mathcal{f} 1976$; 38: $659-64$.

11 Silver MD, Baroldi G, Mariani F. The relationship between acute occlusive coronary thrombi and myocardial infarction studied in 100 consecutive patients. Circulation 1980; 61: 219-27.

12 Friedman M, Manwaring JH, Rosenman RH, Donlon G, Ortega P, Grube SM. Instantaneous and sudden deaths: clinical and pathological differentiation in coronary artery disease. $\mathcal{F} A M A 1973 ; 225$ : 1319-28. 
13 Haerem JW. Mural platelet microthrombi and major acute lesions of main epicardial arteries in sudden coronary death. Atherosclerosis 1974; 19: 529-41.

14 Adelson L, Hoffman W. Sudden death from coronary disease: related to a lethal mechanism arising independently of vascular occlusion or myocardial damage. $\mathcal{F} A M A 1961$; 176: 129-35.

15 O'Reilly RJ, Spellberg RD. Rapid resolution of coronary arterial emboli: myocardial infarction and subsequent normal coronary arteriograms. Ann Intern Med 1974; 81 : 348-50.

16 Richardson PM, Gotsman MS. Angiographic evidence of coronary embolism and resolution. $S$ Afr Med F 1971; 45: 805-9.

17 Fulton WFM, Sumner DJ. Causal role of coronary thrombotic occlusion and myocardial infarction: evidence of stereo-arteriography, serial sections and ${ }^{125}$ I fibrinogen autoradiography (abstract). Am $\mathcal{J}$ Cardiol 1977; 39: 322.

18 Arnett EN, Roberts WC. Acute myocardial infarction and angiographically normal coronary arteries: an unproven combination (editorial). Circulation 1976; 53: 395-400.

19 Rosenblatt A, Selzer A. The nature and clinical features of myocardial infarction with normal coronary arteriogram. Circulation $1977 ; 55$ : 578-80.

20 Hellstrom HR. Evidence in favor of the vasospastic cause of coronary artery thrombosis. Am Heart $\mathcal{F}$ 1979; 97: 449-52.

21 Schwartz CJ, Chandler AB, Gerrity RG, Naito HK. Clinical and pathological aspects of arterial thrombosis and thromboembolism. In: Chandler AB, Eurenius K, McMillan GC, Nelson CB, Schwartz $\mathrm{CJ}$, Wessler S, eds. The thrombotic process in atherogenesis. Advances in experimental medicine and biology. vol. 104. New York: Plenum Press, 1978: 111-26.

22 Hellstrom HR. The injury-vasospasm hypothesis of ischemic heart disease, revisited. Am Heart $\mathcal{F} 1977$; 94: 642-8.

23 Maseri A, L'Abbate A, Baroldi G, et al. Coronary vasospasm as a possible cause of myocardial infarction: a conclusion derived from the study of "preinfarction" angina. $N$ Engl $f$ Med 1978; 299: 1271-7.

\section{Addendum}

After this article was submitted, DeWood et al. ${ }^{1}$ published their data on the high incidence $(69.8 \%)$ of coronary thrombosis in patients undergoing angiography during the early hours of transmural myocardial infarction. Their data suggest that spasm or thrombosis with recanalisation or both may play a significant role in patients during the early course of a transmural myocardial infarction.

\section{Reference}

1 DeWood MA, Spores J, Notske R, et al. Prevalence of total coronary occlusion during the early hours of transmural myocardial infarction. $N$ Engl $\mathcal{f}$ Med 1980; 303: 897-902.

Requests for reprints to Dr David R Holmes Jr, Mayo Clinic, Rochester, Minnesota 55905, USA. 